\title{
Biotinyl-Tyramide-Based In Situ Hybridization Signal Patterns Distinguish Human Papillomavirus Type and Grade of Cervical Intraepithelial Neoplasia
}

\author{
Mark F. Evans, Ph.D., Sharon L. Mount, M.D., Barbara G. Beatty, Ph.D., \\ Kumarasen Cooper, M.B.Ch.B., D.Phil. \\ Department of Pathology, University of Vermont, Burlington, Vermont
}

In this study, the prevalence of human papillomavirus integration in cervical intraepithelial neoplasia Grades I, II, and III has been investigated using a highly sensitive biotinyl-tyramide-based in situ hybridization methodology. This method is able to demonstrate integrated viral DNA by punctate signals within the nucleus and episomal viral DNA by a diffuse signal throughout the nucleus. Fifteen viral types were identified by General Primer 5+/6+ polymerase chain reaction assay among 26 Grade I and 22 Grade II/III lesions. High-risk human papillomavirus (Types 16, 18, 31, 33, 35, 39, 45, 51, 52, 56, 58 , and 66 ) was found in $20(77 \%)$ Grade I and in 22 (100\%) Grade II/III lesions ( $P=.025)$. Human papillomavirus Type 16 was identified in $2(7 \%)$ Grade I and in $15(68 \%)$ Grade II/III samples $(P<.0001)$ and was distinguished from other high-risk types by its demonstration in both Grade I and Grade II/III lesions as frequent punctate signals, detectable at all levels of the epithelium including the basal layer. In contrast, punctate signals, when detected among Grade I lesions that were positive for other high-risk types, did not involve the basal layer and were restricted to occasional cells in the superficial layers. However, Grade II/III lesions positive for high-risk types other than human papillomavirus Type 16 demonstrated frequent punctate signals throughout the epithelium. Overall, punctate signals were detected in $22(100 \%)$ high-risk human papillomavirus-positive Grade II/III lesions and in 5 (25\%) high-risk positive Grade I lesions $(P<$.0001). These data are consistent with human papillomavirus Type 16 possessing a high potential for integration, which may explain its frequent association with cer-

Copyright (C) 2002 by The United States and Canadian Academy of Pathology, Inc.

VOL. 15, NO. 12, P. 1339, 2002 Printed in the U.S.A.

Date of acceptance: September 11, 2002.

Aided by a grant from the Vermont Cancer Center and the Lake Champlain Cancer Research Organization.

Address reprint requests to: Mark F. Evans, Ph.D., Department of Pathology, University of Vermont, Burlington VT 05405; e-mail: mark.evans@uvm.edu; fax: 8026568892. vical intraepithelial neoplasia Grade III and carcinomas. Acquisition of the punctate correlate, especially in the basal layer, is also indicated as important in the development of Grade II/III lesions. The data illustrate the unique potential of biotinyl-tyramide-based in situ hybridization to address key issues concerning the biology of cervical intraepithelial neoplasia.

KEY WORDS: Biotinyl-tyramide, Cervical intraepithelial neoplasia, Human papillomavirus, In situ hybridization, Integration, Physical status.

Mod Pathol 2002;15(12):1339-1347

Human papillomaviruses (HPV) are recognized as a necessary cause of cervical intraepithelial neoplasia (CIN; 1 ), however only a minority of HPV infections ever results in a CIN lesion (2). Although the majority of infections may be cleared by the immune system, much remains to be understood about how persistent infections give rise to lesions of different histological grade and how CIN lesions evolve. It is also unclear why certain high-risk HPV types are significantly more common among high-grade lesions and carcinomas than other high-risk HPV types.

One factor that may be important in CIN progression is integration of HPV sequences into the cell genome. In cell lines and carcinomas, integration has been found to involve disruption and loss of function of the E2 gene that is responsible for regulating expression of the $E 6$ and $E 7$ oncogenes (3). Unregulated high-risk HPV-type $E 7$ expression confers a selective growth advantage on cells in vitro (4), and high-risk E6 and E7 gene expression is associated with loss of cell cycle control and aberrant centrosome function $(5,6)$. Such defects may predispose to the accumulation of genetic anomalies promoting the development of the invasive phenotype (7).

Nonisotopic in situ hybridization has previously been established as a method for the demonstra- 
tion of integrated HPV sequences. Signal patterns were found to match HPV physical status, as determined by analysis of restriction digest patterns/ two-dimensional gel electrophoresis of HPV DNA extracted from cervical tissues (8-10). A discrete, punctate signal pattern within a cell nucleus correlated with integration, whereas a diffuse signal throughout the nucleus indicated episomal HPV. However, until recently, nonisotopic in situ hybridization methodologies have been limited by lack of sensitivity to demonstrate low-copy number integrated HPV sequences.

In this study, a biotinyl-tyramide-based in situ amplification methodology was optimized to enable the reproducible detection of one to two integrated copies of the HPV genome in a model cell line. The aims of the study were to examine the presence of HPV DNA integration in lesions of different pathologic grade and infected with different HPV types and to determine the extent to which in situ hybridization signal patterns distinguish lowand high-grade lesions.

\section{MATERIALS AND METHODS}

\section{Samples}

Twenty-eight CIN I (4 condylomatous) and 22 CIN II/III (9 CIN II, 3 CIN II/III, 10 CIN III) formalin-fixed, paraffin-embedded tissue specimens were obtained from the Fletcher Allen Health Care pathology archives.

\section{DNA Extraction}

For each specimen, three $10-\mu \mathrm{m}$ sections were cut into tubes, dewaxed with xylene, washed with ethanol, and allowed to dry. After overnight digestion at $55^{\circ} \mathrm{C}$ with $400 \mu \mathrm{g} / \mathrm{mL}$ of proteinase $\mathrm{K}$ (Life Technologies) in 200-400 $\mu \mathrm{L}$ of $50 \mathrm{mM}$ Tris- $\mathrm{HCl}$, pH 8.0, tissue debris was pelleted by centrifugation, and the supernatant was used directly for PCR amplification.

\section{PCR of HPV Sequences}

HPV sequences were demonstrated by a modification of the General Primer 5+/6+ PCR assay (11). A $50-\mu \mathrm{L}$ reaction comprised $2-25 \mu \mathrm{L}$ of DNA extract, $1 \times$ PCR reaction buffer (Qiagen), $4 \mathrm{mM}$ of $\mathrm{MgCl}_{2}, 1 \times$ ACGU dNTP mix (Sigma), 1 mM GP5+ primer (5'TTTGTTACTGTGGTAGATACTAC-3'), 1 mM GP6+ primer (5'-GAAAAATAAACTGTAAATCATATTC-3'), 1 U HotStar Taq DNA polymerase (Qiagen), and $0.2 \mathrm{U}$ of $\mathrm{HK}^{\mathrm{TM}}$-Thermolabile Uracil $N$-Glycosylase (Epicentre). PCR cycles comprised a 30-minute incubation at $37^{\circ} \mathrm{C}$ to enable Uracil $N$-Glycosylase function; 15 minutes at $95^{\circ} \mathrm{C}$ to inactivate Uracil $N$-Glycosylase and activate the HotStar Taq; and 40 cycles of 1 minute at $94.5^{\circ} \mathrm{C}, 2$ minutes at $40^{\circ} \mathrm{C}$, and 1.5 minutes at $72^{\circ} \mathrm{C}$. A 5-minute incubation at $72^{\circ} \mathrm{C}$ completed the PCR. Observation of an $~ 150$-base pair PCR product after electrophoresis through $2.5 \%$ agarose gel was taken as evidence of HPV positivity.

\section{Determination of HPV Type}

Two microliters of heat-denatured PCR product was spotted onto a nylon membrane, baked at $80^{\circ} \mathrm{C}$ for 2 hours, ultraviolet fixed by Stratalinker (Stratagene), and prehybridized at $55^{\circ} \mathrm{C}$ for 2 hours with $2 \times$ SSC, $0.1 \%$ lauryl sarcosine, $0.02 \%$ SDS, and $1 \%$ blocking reagent (Roche Diagnostics). Membranes were hybridized overnight with $20 \mathrm{pmol} / \mathrm{mL}$ biotinlabeled HPV type-specific oligonucleotides. Oligoprobes to 22 HPV types were used in this study (HPV types 6, 11, 16, 18, 31, 33-35, 39, 40, 42-45, 51, $52,54,56,58,59,66$, and 68; 11). Membranes were washed at $55^{\circ} \mathrm{C}$ in $2 \times$ SSC, $0.1 \%$ SDS three times for 10 minutes, then blocked at $20^{\circ} \mathrm{C}$ in $100 \mathrm{mM}$ Tris$\mathrm{HCl}, \mathrm{pH} 8.0 ; 100 \mathrm{mM} \mathrm{NaCl}$; and $1 \%$ blocking reagent for 1.5 hours, and the biotin label was demonstrated using the BluGene detection system (Life Technologies).

\section{In Situ Hybridization}

In situ hybridization was performed using individual plasmid probes (for Types $6^{*}, 11,16,18^{*}, 31^{*}$, 33, 35* $43^{*}, 56^{*}$; *American Tissue Culture Collection) labeled with biotin by nick translation (Life Technologies). A wide spectrum HPV probe (DAKO) was used in cases for which the specific probe was not available.

The GenPoint Catalyzed Signal Amplification System (DAKO) was optimized for reproducible sensitive and background free usage. Formalinfixed, paraffin-embedded SiHa cells that contain one to two copies of HPV 16 integrated at chromosome 13q, HeLa cells that contain $\leq 50 \mathrm{HPV} 18$ copies integrated at five sites and CaSki cells that contain $\leq 600$ HPV 16 copies integrated at multiple sites, and carcinoma tissues were used as model systems (12).

Tissue sections $6 \mu \mathrm{m}$ thick were cut onto ADCELL slides (Erie Scientific Company) and dried overnight at $55^{\circ} \mathrm{C}$. Tissues were dewaxed in two 5 -minute changes of xylene followed by graded $(100-70 \%)$ ethanol washes. After rinsing in water, tissues were air dried and then immersed for 40 minutes in a Coplin jar containing $10 \mathrm{mM}$ sodium citrate, $\mathrm{pH}$ 6.0, pre-equilibrated to temperature in a water bath set at $95.0^{\circ} \mathrm{C}$. The Coplin jar was then removed from the water bath and allowed to cool at room temperature for 20 minutes. The slides were rinsed with water and air dried. Tissues were then digested at $25^{\circ} \mathrm{C}$ with $100 \mu \mathrm{g} / \mathrm{mL}$ pepsin (Sigma 
$\mathrm{P}-7012)$ in $0.2 \mathrm{M} \mathrm{HCl}$. Digestion times were optimized for each sample and ranged from 5 to 45 minutes, with 20 minutes being most typically optimal. Slides were rinsed three times for 5 minutes each in PBS $(0.01 \mathrm{M}$ phosphate, $0.027 \mathrm{M} \mathrm{KCl}, 0.137$ $\mathrm{M} \mathrm{NaCl}, \mathrm{pH} 7.4$ ) and $0.05 \%$ Tween 20 , followed by three 5-minute rinses in PBS and water and air drying.

Hybridization mixture was applied directly to the tissue section and comprised $50 \%$ formamide; $10 \%$ dextran sulfate; $2 \times \mathrm{SSC}, \mathrm{pH} 7.0 ; 400 \mathrm{ng} / \mu \mathrm{L}$ sonicated human placental DNA (Sigma); and $2 \mathrm{ng} / \mu \mathrm{L}$ HPV probe. Coverslipped slides were placed into Terasaki plates (Nunc) containing $5 \times$ SSC. The plates were laid onto a $1.5-\mathrm{cm}$-thick aluminium plate in an oven set at $95^{\circ} \mathrm{C}$ for 15 minutes to enable simultaneous denaturation of probe and target sequences. Biotinylated plasmid probe (pUC) was used as a negative control. Tissues were hybridized overnight at $37^{\circ} \mathrm{C}$. Coverslips were removed by rinsing the slides in $300 \mathrm{mM} \mathrm{NaCl} ; 50 \mathrm{mM}$ Tris- $\mathrm{HCl}$, pH 7.6; and $0.05 \%$ Tween 20. Samples were washed at high stringency $\left(0.1 \times \mathrm{SSC}\right.$ at $55^{\circ} \mathrm{C}$, twice for 10 min), or low stringency $\left(2 \times \mathrm{SSC}\right.$ at $37^{\circ} \mathrm{C}$, twice for $10 \mathrm{~min}$ ) when the wide-spectrum probe was used.

Detection of biotin was performed according to the GenPoint protocol replacing diaminobenzidine chromogen with aminoethylcarbazole. Primary streptavidin horseradish-peroxidase conjugate used at a dilution of 1:500 was found sufficient to demonstrate the integrated HPV copies in the SiHa, $\mathrm{HeLa}$, and CaSki cell preparations and carcinomas and so was used as the standard dilution (Fig. 1A). Dilutions as low as 1:5000 were also used to confirm that diffuse signal did not represent coalescence of signals from HPV integrated at high copy number. Biotinyl-tyramide and secondary streptavidinhorseradish peroxidase conjugate were used as supplied in the GenPoint kit. Aminoethylcarbazole (Sigma) was applied to sections for 10 minutes. Sections were counterstained with hematoxylin and mounted in glycerol gelatin (Sigma).

\section{Statistics}

For analytical purposes, CIN II and III samples were combined as one group. Fisher's exact test and odds ratio (OR) with $95 \%$ confidence intervals (CI) were performed using software supplied by GraphPad InStat (San Diego, CA).

\section{RESULTS}

\section{HPV Type}

The data from this study are summarized in Tables 1 and 2. A total of 15 HPV types was identified using the panel of 22 oligonucleotide probes. Four- teen types were positively identified among the CIN I samples, and 7 among the CIN II/III. PCR products that could not be specifically typed with the oligonucleotide panel were obtained from two CIN I lesions.

Classifying HPV types into low-risk types (e.g. 6, 11,43 ) and high-risk types (e.g. 16, 18, 31, 33, 35, 39, $45,51,52,56,58$, and 66 ; 11) demonstrated that all $22 \mathrm{CIN}$ II/III lesions were high-risk positive and that 20 of 26 (77\%) CIN I (known risk types) were highrisk positive. The association of high-risk types with CIN II/III tissues was significant $(P=.025$; OR $=$ 14.268, 95\% CI: 0.755-269.56). The distribution of HPV Type 16 between the CIN grades was highly significant. Two of 28 (7\%) CIN I and 15 of $22(68 \%)$ CIN II/III samples were positive for HPV 16 ( $\mathrm{P}<$ $.0001 ;$ OR $=27.857,95 \%$ CI: 5.112-151.81).

\section{Signal Type \\ CIN I}

Twenty of 28 (71\%) CIN I samples demonstrated diffuse signals only. Three of these samples were low-risk positive, 15 were high-risk positive, and 2 were positive for unidentified HPV types. Eight CIN I lesions demonstrated punctate only or punctatediffuse signals. Three of these were positive for lowrisk HPV types, and five were high-risk positive. Of these three low-risk samples, one HPV 43-positive, highly focal lesion demonstrated only punctate signal. An HPV 11-infected lesion demonstrated predominantly punctate signals with occasional diffuse signals ( $<5 \%$ of cells; Fig. 1B). One HPV 6 CIN I lesion demonstrated predominantly diffuse signals with punctate signals in $\sim 10 \%$ of the cells demonstrating in situ hybridization signals. In each of these three cases, punctate signals were detected only in mid- to superficial layers.

Of the five high-risk positive CIN I lesions demonstrating punctate signals, two were HPV 16 positive. Approximately $30 \%$ of cells demonstrating in situ hybridization signals contained punctate signal, and these two were the only CIN I lesions in which basal punctate signal was detected (Fig. 1C). In the three other punctate-diffuse high-risk positive CIN I samples, punctate signals were present in $<5 \%$ of cells and were restricted to occasional cells in the superficial layer (Fig. 1D).

One CIN I (HPV 45-positive) tissue block retrieved from archives contained three separate pieces of biopsied tissue. Morphologically defined CIN I was present on two pieces. Only intense diffuse staining was demonstrated, and this was confined to the mid- to superficial layers (Fig. 1E). The third tissue piece, which was morphologically normal by review of preceding and subsequent hematoxylin and eosin-stained sections as well as review 

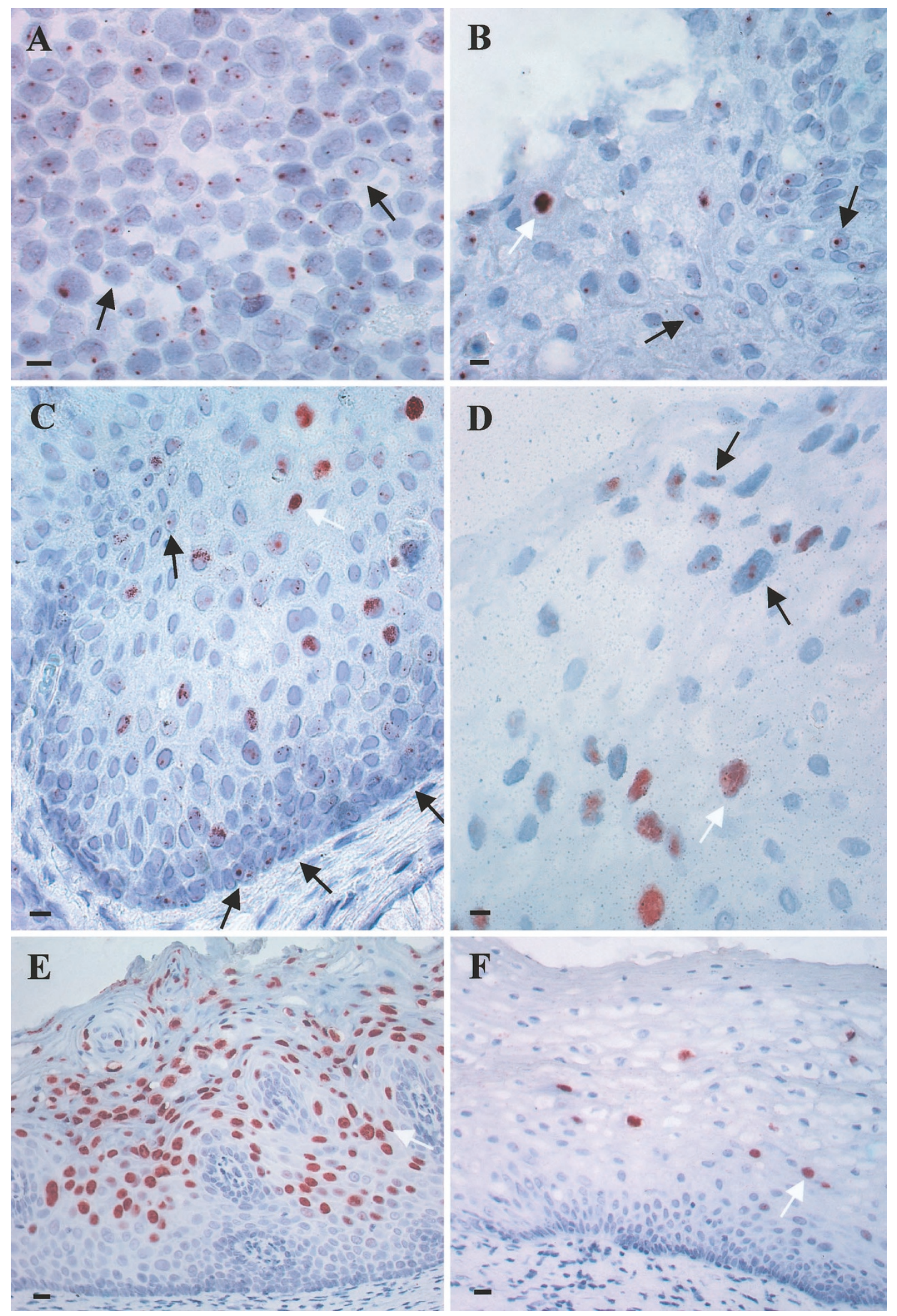

FIGURE 1. Punctate and diffuse signals in the SiHa cell line and CIN I lesions. A, punctate signals in SiHa cells known to contain one to two copies of HPV 16. B, HPV 11-positive condylomatous CIN I demonstrating a predominantly punctate signal pattern with occasional diffuse signals at the lesion surface. C, HPV 16-positive CIN I demonstrating diffuse signals and punctate signals that are detectable in the basal layer. D, HPV 52-positive CIN I demonstrating occasional punctate signals in the surface layers. E, typical diffuse CIN I-staining pattern demonstrated in HPV 45infected tissue. F, morphologically normal tissue from the same HPV 45-positive specimen (Fig. 1C), also demonstrating diffuse signals. Black arrows, punctate signal; white arrows, diffuse signal; Panels A, B, E, and F, scale bar, $10 \mu \mathrm{m}$; Panels $\mathbf{C}$ and D, scale bar, $20 \mu \mathrm{m}$. 
TABLE 1. HPV Types and Signal Types in CIN I Specimens

\begin{tabular}{|c|c|c|c|c|c|c|c|c|c|c|c|c|c|c|c|c|}
\hline HPV Type & 6 & $6 \& 43$ & 11 & 16 & 18 & 31 & 33 & 35 & 39 & 43 & 45 & 51 & 52 & 56 & 66 & $\mathrm{U}$ \\
\hline $\begin{array}{l}\text { Number of Cases } \\
\quad(n=28)\end{array}$ & 1 & 1 & 1 & 2 & 1 & 2 & 1 & 1 & 3 & 3 & 1 & 3 & 2 & 1 & 3 & 2 \\
\hline Signal Type D & & 1 & & & 1 & 2 & 1 & 1 & 3 & 2 & 1 & 2 & 1 & 1 & 2 & 2 \\
\hline$D \& P$ & 1 & & 1 & 2 & & & & & & & & 1 & 1 & & 1 & \\
\hline $\mathrm{P}$ & & & & & & & & & & 1 & & & & & & \\
\hline
\end{tabular}

D, diffuse; D \& P, diffuse and punctate; P, punctate.

of in situ hybridization-processed tissues, also demonstrated diffuse signal (Fig. 1F).

CIN I lesions ranged in size from $<1$ high-power $(400 \times$ ) field (HPV 43 positive) to $7.5 \mathrm{~mm}$ in length (HPV 45 positive).

\section{CIN II/III}

All 22 (100\%) CIN II/III lesions demonstrated punctate signals (compared with $8 / 28$ CIN I: $P<$ .0001 ; OR $=108.53$, 95\% CI: 5.833-2002.2; Table 2). Three (14\%) CIN II/III specimens demonstrated punctate signals only (Fig. 2A), and 19 (86\%), punctate and diffuse. Among these 19, the number of stained cells containing only punctate signals ranged from $30-80 \%$.

HPV DNA was detectable by biotinyl-tyramidebased in situ hybridization at all levels of the epithelium, including the basal and parabasal layers in all but two CIN II specimens (one HPV 45-positive, one focal HPV 58-positive lesion). Intense diffuse signals either were present in the middle and parabasal regions (Fig. 2B) or were confined to the superficial layers (Fig. 2C). Punctate and diffuse signals were in all cases distributed across the entire lesion. There was no evidence of emergent foci of diffuse-punctate or punctate-only signals arising within a lesion that otherwise demonstrated a diffuse-only signal pattern across its length. There was heterogeneity across large CIN II/III lesions with respect to proportion of punctate to diffuse cell signals and depth within epithelium at which diffuse signals were detectable. One lesion demonstrated punctate and diffuse signals for most of its length but also included a region of punctate-only signals (Fig. 2C-D). Cell-to-cell heterogeneity was also evident, with intense diffuse cells being found directly adjacent to punctate cells in superficial layers (Fig. 2C). CIN II/III lesions ranged in size from

TABLE 2. HPV Types and Signal Types in CIN II/III Specimens

\begin{tabular}{lrcccccc}
\hline HPV Type & 16 & 18 & 31 & 33 & 45 & 56 & 58 \\
\hline $\begin{array}{l}\text { Number of Cases } \\
\quad\end{array}$ & 15 & 1 & 2 & 1 & 1 & 1 & 1 \\
$\begin{array}{l}\text { Signal Type } \\
\quad \text { D \& P }\end{array}$ & 14 & 1 & 1 & & 1 & 1 & 1 \\
$\quad \mathrm{P}$ & 1 & & 1 & 1 & & & \\
\hline
\end{tabular}

D \& P, diffuse and punctate; P, punctate.
$<1$ high-power $(400 \times)$ field (HPV $45-$ and HPV 58 -positive) to $1.5 \mathrm{~cm}$ in length (HPV 16-positive).

In addition to SiHa cells, punctate signals were readily detectable in CaSki and HeLa cell preparations as well as in carcinoma samples, and specimens probed with biotinylated pUC demonstrated no signal (data not shown).

\section{DISCUSSION}

The major finding of this study is that biotinyltyramide-based in situ hybridization signal patterns distinguish HPV 16 from other HPV types and also distinguish CIN I from CIN II/III lesions. Punctate signals were invariably detectable in the basal layers of HPV 16-positive CIN I or CIN II/III lesions. Other HPV types demonstrated basal signals only in CIN II/III lesions (Fig. 2A-F). Punctate signals were rare and confined to occasional superficial cells in high-risk HPV (non-HPV 16 positive) infected CIN I lesions but were common when these types were found among CIN II/III tissues. These findings have implications for understanding HPV integration, significance of HPV type, and CIN progression.

\section{HPV and Integration}

This study has demonstrated that HPV DNA integrated into the cell genome is detectable as punctate signals by biotinyl-tyramide-based in situ hybridization (Fig. 1A). Application of this technique to $50 \mathrm{CIN}$ lesions suggests that the presence of integration is a defining feature of CIN II/III. This finding is in agreement with previous estimates of integration prevalence among CIN II/III lesions (13-15). It is also in agreement with analyses of HPV DNA open-reading frame transcription patterns obtained after in situ hybridization assay with radiolabeled riboprobes. Stoler et al. (16) found that 15 of 16 (94\%) HPV 16-infected CIN III lesions demonstrated open-reading frame transcription patterns that were consistent with the presence of both episomal and integrated HPV DNA. Two HPV 18positive CIN III tissues examined in the same study both demonstrated transcription patterns consistent with the presence of integrated sequences alone. However, the data contrast with other estimates that integration is found in $5-50 \%$ of CIN 


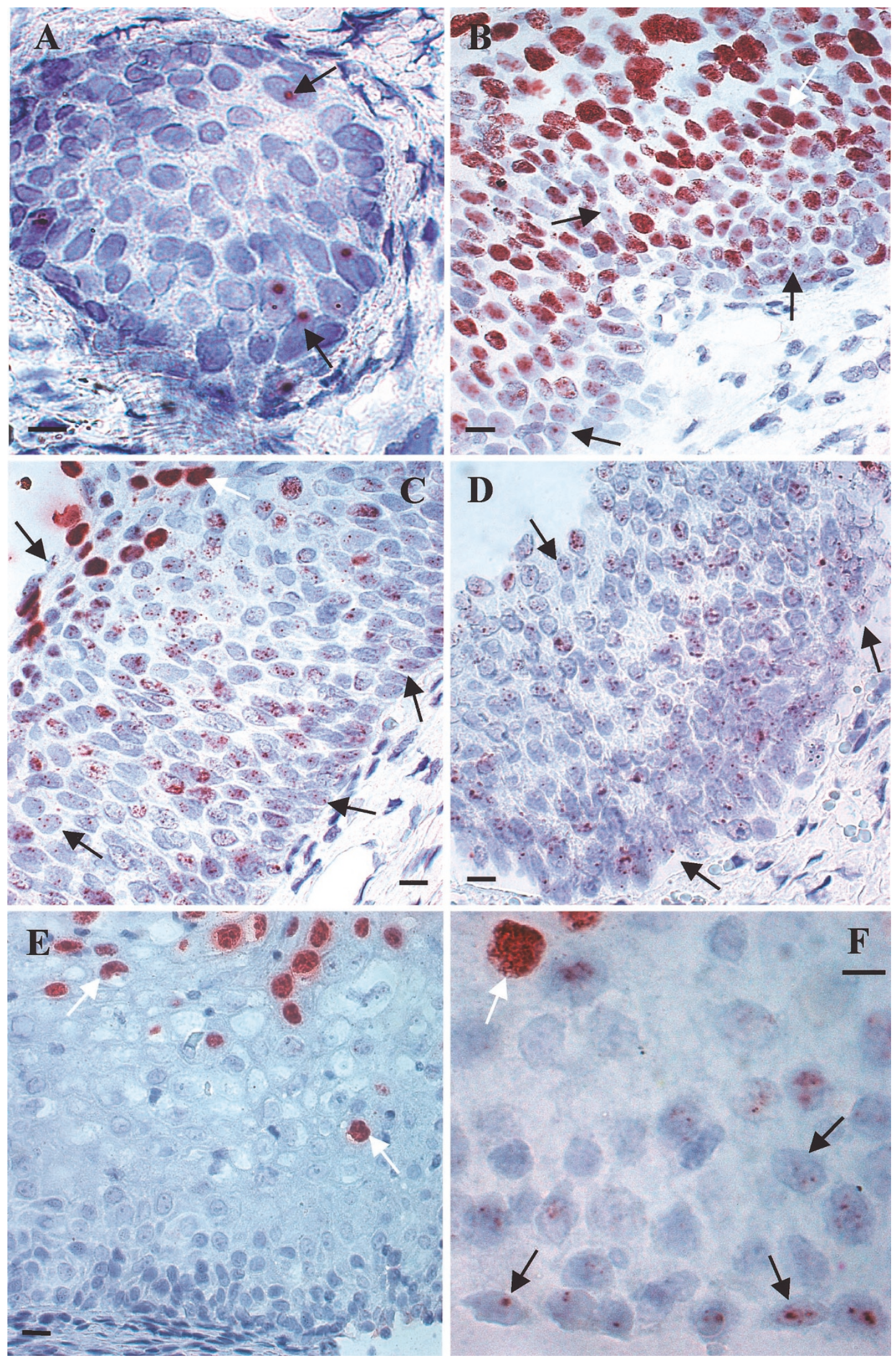

FIGURE 2. Punctate and diffuse signals in CIN II/III lesions and demonstration of basal cell punctate signal distinguishing HPV 18-infected CINI from HPV 18-infected CIN II. A, basal punctate signals from an HPV 33-positive CIN III that had spread into an endocervical gland (from a lesion demonstrating punctate signals only). B, punctate and diffuse signals that extend to the parabasal layer in an HPV 16-positive CIN II. C, HPV 16-positive CIN III demonstrating diffuse signals only at the surface layers and punctate signals in all layers. D, a region of punctate-only signals from a continuation of the same lesion shown in Figure 2C. E, basal punctate signals were absent in non-HPV 16 positive CIN I tissues as demonstrated in this HPV 18-infected CIN I. F, basal signals evident in an HPV 18-positive CIN II. Black arrows, punctate signal; white arrows, diffuse signal; scale bar, $10 \mu \mathrm{m}$. 
II/III lesions (17-21). Technical difficulties may account for the contradictory findings. Previous estimates of integration have required fresh tissue specimens for analysis. Patient diagnostic requirements permit only limited quantities of unfixed tissues for experimental analysis. Sensitivity is therefore a key issue, with the detection of integration depending on the quantity and quality of nucleic acid available for analysis. As noted by Cullen et al. (18), concomitant episomal forms can mask the presence of relatively small amounts of integrated HPV DNA. An RT-PCR assay based on the finding that HPV RNA integrate-derived transcripts contain host cellular sequences was designed to detect integrated HPV sequences in the presence of episomal HPV (21). Nevertheless, the method is still dependent on threshold levels of target RNA in the sample tissue analyzed. All of these techniques presuppose that CIN lesions are relatively homogenous with respect to integration status. In situ hybridization allows direct cell-by-cell visualization of events by light microscopy. Thus, the presence of HPV DNA integration in a minority of cells within a lesion is potentially measurable, and the technique is not subject to the sensitivity limitations of other methodologies. Punctate signals were detectable in tissues demonstrating intense and abundant diffuse signals (Fig. 2B-C) that were consistent with the underestimation of integration levels because of episomal masking (18).

The findings of the present study suggest that low-risk HPV type DNA can also become integrated into the cell genome. These lesions were low grade, in line with the oncogenic character of these HPV types (3). Further investigation is required of this finding and also of the significance of basalcompared with mid- or superficial-layer punctate signals. Integration may occur in the basal layer through disruption of constitutive cell cycle control, and/or integration can also be initiated in other epithelial layers through disruption of differentiation-maturation control pathways.

Punctate signal has been interpreted in this study as evidence of integration. All available experimental precedents (e.g. correlation of signal patterns with Southern blot assays and in situ hybridization of cell lines) indicate that punctate signals represent integration of viral DNA into the cell genome. It is also possible to accommodate this interpretation with previous studies of integration as detailed above. Moreover, punctate signals were found associated with increasing pathologic grade of cervical lesion, and this is also readily explainable by accepting punctate signals to be representative of integration. However, it cannot be stated categorically that every punctate signal represents integration. Further confirmation of this interpretation is required, as several issues require clarification.
Primary HPV infection is understood to occur in the basal and parabasal layers of the cervical epithelium, and productive viral replication is linked to epithelial differentiation, which takes place in the mid and superficial layers (3; Figs. 1E and 2E). The absence of in situ hybridization signals in the basal and parabasal layers of CIN I lesions (other than those infected with HPV 16) has been interpreted in this study as failure of the biotinyltyramide assay to detect low-copy number HPV when in the form of $\sim 8$ kilo-base pair episomes, as they may represent too scattered a target. In contrast it is suggested that HPV, when physically integrated into the host-cell chromosomes, is detectable at low-copy number, as the DNA is then a relatively more concentrated target. Absence of punctate or diffuse signal in every cell within a lesion is accounted for in terms of loss of low-copy number target DNA because of tissue sectioning. In addition, clarification is required of the speculation that low-copy number HPV concatamers comprising compounded multiple units of the HPV genome may also be represented by punctate signals.

There are no model systems available that contain low-copy, $\sim 8$ kilobase episomal or concatameric HPV molecules to examine these issues. Resolution of such uncertainties may be possible by combining biotinyl-tyramide-based in situ hybridization with electron microscopy and/or confocal microscopy techniques on pathology samples. PCR analysis of (laser-capture) microdissected epithelial layers may also assist in physical status assessment.

\section{HPV Type and CIN Grade}

HPV 16 was the most frequently identified type among CIN II/III tissues, in agreement with results of previous studies (22). The significantly uneven distribution of HPV 16 prevalence between CIN grades supports the contention that CIN II/III lesions can arise de novo (23) and/or that HPV 16infected CIN I may rapidly progress to high grade. For example, a longitudinal study of young women who had recently become sexually active found that the risk of CIN III was greatest in those who tested positive for HPV 16 and that this risk was maximum just 6-12 months after first detection of HPV 16 (24).

\section{CIN Progression}

The data from this study support a hypothesis that HPV 16 DNA may readily integrate into the cell genome. Disruption of the E2 open-reading frame and unregulated E6/E7 activity may then explain the common association of HPV 16 and not other high-risk HPV types with high-grade lesions and invasive disease, as well as the uneven distribution 
of HPV 16 between CIN grades. Further, punctate signals were rare among CIN I lesions infected with non-HPV 16 high-risk types, but common when these types were associated with CIN II/III tissues (Fig. 2E-F). This finding suggests that acquisition of the punctate correlate, especially in the basal layer, is critical for the development of a high-grade lesion.

Acquisition of the punctate signal correlate is also indicated as occurring early in CIN II/III development because there was no evidence of incipient punctate or of punctate-diffuse foci arising within a diffuse-classified CIN II/III lesion. In addition, focal CIN II/III tissues demonstrated punctate signals, suggesting that they arose de novo and not via progression from diffuse (episomal) states. This concept is also supported by the demonstration that CIN II/III lesions associated with high-risk types have a monoclonal origin (25). Secondary clonal expansions may subsequently give rise to punctatediffuse signal type heterogeneity and other forms of intralesional heterogeneity, such as allelic imbalance (26). A high prevalence of integration in CIN II/III lesions is consistent with the development of invasive capacity, depending not on integration per $s e$ (which may of itself support cell proliferation; 4) but on the (stochastic) acquisition of key genetic defects (7) subsequent to loss of E6/E7 regulation.

The demonstration of high-risk HPV in histologically normal tissue is, to the authors' knowledge, the first by in situ hybridization and supports the report of high-risk HPV in cytologically normal samples (11). Further study of the prevalence of such diffuse signal (episomal HPV) in "normal" female (and male) tissues and of the relationship to progression to recognizable CIN is required.

In summary, biotinyl-tyramide-based in situ hybridization is an emerging technology that allows sensitive direct visualization of HPV at the lightmicroscopic level. Although larger studies are needed, the data from this study demonstrate the potential of the technique to provide an increased understanding of cervical intraepithelial neoplasia.

Acknowledgements: Probes for HPV Types 11 and 16 were received courtesy of Dr. E.-M. de Villiers, Deutsches Krebsforschungszentrum (DKFZ), Heidelberg, Germany. The HPV type 33 probe was received from Dr. G. Orth, Institut Pasteur, Paris, France.

\section{References}

1. Schiffman MH, Bauer HM, Hoover RN, Glass AG, Cadell DM, Rush BB, et al. Epidemiologic evidence showing that human papillomavirus infection causes most cervical intraepithelial neoplasia. J Natl Cancer Inst 1993;85:958-64.
2. Meijer CJ, Walboomers JM. Cervical cytology after 2000: where to go? J Clin Pathol 2000;53:41-3.

3. Syrjanen K, Syrjanen S. Molecular biology of papillomaviruses. In: Syrjanen K, Syrjanen S, editors. Papillomavirus infections in human pathology. 1st ed. New York: Wiley; 2000. p. 11-51.

4. Jeon S, Allen-Hoffmann BL, Lambert PF. Integration of human papillomavirus type 16 into the human genome correlates with a selective growth advantage of cells. J Virol 1995; 69:2989-97.

5. Southern SA, Herrington CS. Disruption of cell cycle control by human papillomaviruses with special reference to cervical carcinoma. Int J Gynecol Cancer 2000;10:263-74.

6. Duensing S, Lee LY, Duensing A, Basile J, Piboonniyom S, Gonzalez S, et al. The human papillomavirus type 16 E6 and E7 oncoproteins cooperate to induce mitotic defects and genomic instability by uncoupling centrosome duplication from the cell division cycle. Proc Natl Acad Sci U S A 2000; 97:10002-7.

7. Galloway DA, McDougall JK. The disruption of cell cycle checkpoints by papillomavirus oncoproteins contributes to anogenital neoplasia. Semin Cancer Biol 1996;7:309-15.

8. Cooper K, Herrington CS, Stickland JE, Evans MF, McGee JO. Episomal and integrated human papillomavirus in cervical neoplasia shown by non-isotopic in situ hybridisation. J Clin Pathol 1991;44:990-6.

9. Kristiansen E, Jenkins A, Holm R. Coexistence of episomal and integrated HPV16 DNA in squamous cell carcinoma of the cervix. J Clin Pathol 1994;47:253-6.

10. Berumen J, Unger ER, Casas L, Figueroa P. Amplification of human papillomavirus types 16 and 18 in invasive cervical cancer. Hum Pathol 1995;26:676-81.

11. Jacobs MV, Walboomers JM, Snijders PJ, Voorhorst FJ, Verheijen RH, Fransen-Daalmeijer N, et al. Distribution of 37 mucosotropic HPV types in women with cytologically normal cervical smears: the age-related patterns for high-risk and low-risk types. Int J Cancer 2000;87:221-7.

12. Meissner JD. Nucleotide sequences and further characterization of human papillomavirus DNA present in the CaSki, SiHa and HeLa cervical carcinoma cell lines. J Gen Virol 1999;80:1725-33.

13. Shirasawa H, Tomita Y, Kubota K, Kasai T, Sekiya S, Takamizawa $\mathrm{H}$, et al. Detection of human papillomavirus type 16 DNA and evidence for integration into the cell DNA in cervical dysplasia. J Gen Virol 1986;67:2011-5.

14. Lehn H, Villa LL, Marziona F, Hilgarth M, Hillemans HG, Sauer G. Physical state and biological activity of human papillomavirus genomes in precancerous lesions of the female genital tract. J Gen Virol 1988;69:187-96.

15. Daniel B, Mukherjee G, Seshadri L, Vallikad E, Krishna S. Changes in the physical state and expression of human papillomavirus type 16 in the progression of cervical intraepithelial neoplasia lesions analysed by PCR. J Gen Virol 1995;76:2589-93.

16. Stoler MH, Rhodes CR, Whitbeck A, Wolinsky SM, Chow LT, Broker TR. Human papillomavirus type 16 and 18 gene expression in cervical neoplasias. Hum Pathol 1992;23: $117-28$.

17. Fukushima M, Yamakawa $Y$, Shimano S, Hashimoto M, Sawada Y, Fujinaga K. The physical state of human papillomavirus 16 DNA in cervical carcinoma and cervical intraepithelial neoplasia. Cancer 1990;66:2155-61.

18. Cullen AP, Reid R, Campion M, Lorincz AT. Analysis of the physical state of different human papillomavirus DNAs in intraepithelial and invasive cervical neoplasm. J Virol 1991; 65:606-12.

19. Pirami L, Giache V, Becciolini A. Analysis of HPV 16, 18, 31 and 35 DNA in pre-invasive and invasive lesions of the uterine cervix. J Clin Pathol 1997;50:600-4. 
20. Das BC, Sharma JK, Gopalakrishna V, Luthra UK. Analysis by polymerase chain reaction of the physical state of human papillomavirus type 16 DNA in cervical preneoplastic and neoplastic lesions. J Gen Virol 1992;73:2327-36.

21. Klaes R, Woerner SM, Ridder R, Wentzensen N, Duerst M, Schneider A, et al. Detection of high-risk cervical intraepithelial neoplasia and cervical cancer by amplification of transcripts derived from integrated papillomavirus oncogenes. Cancer Res 1999;59:6132-6.

22. Matsukura T, Sugase M. Relationships between 80 human papillomavirus genotypes and different grades of cervical intraepithelial neoplasia: association and causality. Virology 2001;283:139-47.
23. Burghardt E, Ostor AG. Site and origin of squamous cervical cancer: a histomorphologic study. Obstet Gynecol 1983;62:117-27.

24. Woodman CB, Collins S, Winter H, Bailey A, Ellis J, Prior P, et $a l$. Natural history of cervical human papillomavirus infection in young women: a longitudinal cohort study. Lancet 2001;357:1831-6.

25. Park TW, Richart RM, Sun XW, Wright TC Jr. Association between human papillomavirus type and clonal status of cervical squamous intraepithelial lesions. J Natl Cancer Inst 1996;88:355-8.

26. Evans MF, Koreth J, Bakkenist CJ, Herrington CS, McGee JO. Allelic deletion at 11q23.3-q25 is an early event in cervical neoplasia. Oncogene 1998;16:2557-64. 